\title{
Identidad personal y narración: una lectura ${ }^{1}$
}

\author{
María Rosa Palazón
}

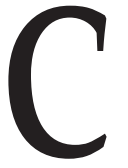

oincidiendo con Chisholm -Person and Object-, Paul Ricoeur pregunta: ¿quién es la persona de que hablan la narrativa, las descripciones o es motivo de "imputación" 2 moral? Sí mismo como otro aclara que el calificativo que aparece en el título, "sí mismo", puede sustituirse por cualquier pronombre personal. Lo abordaré en tanto yo persona y personaje narrativo.

1. Como suponer una identidad no identificable es una contradicción, al sí mismo se atribuye una singularidad: se define como uno y único. Esto es, le atribuimos una personalidad, no por los elementos o las características que lo constituyen, sino por la manera en que los estructura y por las respuestas que da a unas circunstancias. Aisladamente, en tanto que cada persona es un Dasein -es y está en cronotopo y unas tradiciones comunes, en un sedimento cultural que internaliza-, la identidad supone la "identificación-con" que ocurre en el "reconocerse-en". ${ }^{3}$ El ser en el mundo o ser con que somos, aprende que los otros no son radicalmente diferentes, sino en algunos aspectos un alter ego. ${ }^{4}$ Dentro de esta comunidad, somos un sí mismo o persona en tanto holon, lo mío en cada caso, es un todo que se forma y conforma: "es un concepto de relación y una relación de relaciones". 5

2. Retomando el asunto que ha ocupado a la filosofía, aproximándola a la ciencia ficción, Ricoeur define al sí mismo como una identidad idem o

${ }^{1}$ Esta ponencia se presentó el 10 de agosto de 2003, en versión española y en traducción al inglés, en el XXIst. World Congress of Philosophy que se realizó en Estambul, Turquía.

${ }^{2}$ Paul Ricoeur, Soi-même comme un autre. París, Seuil, 1990. (Essais, 360)

${ }^{3}$ Ibid., p. 146.

${ }^{4}$ Ibid., pp. 380-392.

${ }^{5}$ Ibid., p. 140. 
mismidad, y como una identidad ipse, que han abordado las filosofias historicistas, particularmente Dilthey y Heidegger, así como la narración y las teorías literarias.

Como mismidad (idem en latín, sameness en inglés y Gleichheit en alemán), la identidad es numérica y geométricamente un centro de arraigo y acumulativo de experiencias. Su contrario es la pluralidad. Las relaciones ocurren en un punto, no están dispersas. En tanto holon mis experiencias son intransitivas: se me "apresentan", ${ }^{6}$ mientras que las de los demás me son presentadas. Este centro, el yo, al cual se atribuyen predicados físicos y psíquicos, se ha localizado en el cuerpo, o dimensión espacial que trataron Nietzsche y Husserl, entre otros. El cuerpo establece la frontera entre el "quién" y lo otro y los otros. Distingue al sí mismo del mundo: la identidad requiere la corporeidad y la mundanidad, ${ }^{7}$ concluye Ricoeur. En relación con este centro, algunas filosofías disgregaron o atomizaron al sí mismo para encontrar en algunas de sus experiencias concretas su mismidad. El resultado es un arcano. Hume en el libro I del Tratado de la naturaleza humana pensó la sameness como la invariable en el curso temporal de una vida, y la graduó. Debido a su dogma empirista, buscó una impresión perceptiva que pudiera señalarse como mismidad. Como no la descubrió, la redujo a una ilusión. Lo único real son los vínculos asociativos: la mismidad es como una Commonwealth, porque cambian sus miembros, no las relaciones, dijo Hume.

En "identidad y diversidad" -Ensayo sobre el entendimiento humano-, Locke considera que la identidad idem se extiende en el tiempo mediante la memoria. En ésta la dejó suspendida, con sus límites, fallos y carácter intermitente (por ejemplo debido al sueño). "Como yo pienso" no es igual a "se piensa" y, por lo tanto, el encadenamiento (connectedness) de datos ha de ocurrir en un espacio señalable, este lugar privilegiado de la identidad se ubicó en el sistema nervioso y destacadamente en el cerebro. Entonces, los discípulos de Locke imaginaron irresolubles casos rompecabezas (puzzling cases) sobre el trasplante de cerebro, las bisecciones, la reduplicación, el teletransporte y el caso clínico de desdoblamiento de la personalidad. Por ejemplo, si el cerebro de alguien es trasplantado a una réplica y el original desaparece, o sea, si se logra que la identidad deje de ser numéricamente una, ¿la identidad personal sigue siendo la misma? La primera objeción a estos planteamientos es que el cerebro no está dado a los sentidos: es "interioridad no vivida". ${ }^{8}$ La segunda, recogida por Parfit, ${ }^{9}$ es que el cerebro no es una personalidad: no pueden

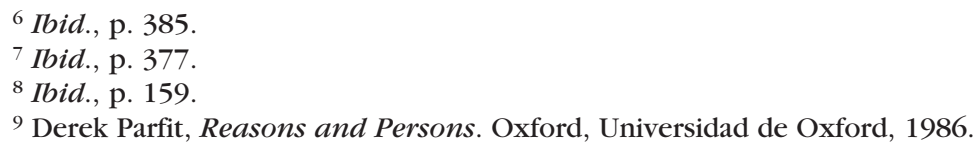


disasociarse las partes de la identidad, llenas de nexos. Como se encuentra un soporte firme al cual atribuir la identidad, concluye que la "identidad personal no es lo que cuenta". ${ }^{10}$ Después pasa a cuestiones éticas o al desposeimiento altruista. Sin embargo, no es posible resolver cuestiones éticas sin determinar qué clase de entidades son las personas: es necesario que sean dueñas de sí, con una autonomía que determina su toma de decisiones. Si no, la ética resulta incomprensible. También, el derecho o cualquier imputación. Si olvidáramos la identidad idem, ejemplifica Ricoeur, no podrían resolverse los casos de culpabilidad por un crimen.

En la vida cotidiana se consideran distintivos de la mismidad la fidelidad a la palabra empeñada (que abarca un intervalo o dirección de sentido) y su cumplimiento, junto con el carácter, o "valor emblemático" ${ }^{11}$ de la personalidad, en tanto reúne la identidad numérica y cualitativa. En Le volontaire et l'involontaire, Ricoeur mismo precisó que, si no lo reducimos a lo involuntario, y si lo puntualizamos como una disposición adquirida, el carácter es algo que permite, en un corte sincrónico, distinguir a una persona de otra. ${ }^{12}$ Tal duración es temporal: las disposiciones cambian, se van adquiriendo nuevas "identificaciones con-sedimentadas". ${ }^{13}$ Si se considera permanente al carácter, se cae en las peores ideologías sobre la identidad ${ }^{14}$ que oculta el ipse en el idem.

J. Naberet, G. Marcel y E. Levinas han dado primacía al otro, al distinto de sí, en la construcción de la identidad. Para Ricoeur, en tanto el yo cambia, el otro incluso se halla en el sí mismo. Esta otredad la llama identidad ipse (selfhood en inglés y Selbstheit en alemán), que no registró la filosofía analítica. Cualitativamente, la identidad no es una sustancia invariable o "continuidad ininterrumpida", ${ }^{15}$ sino que se desarrolla en serie. Precisamente la conexión de vida (Zusammenhang des Lebens), según Dilthey, es histórica, con unos ritmos de cambio (por ejemplo, la acumulación de cambios débiles acaba en uno radical). La permanencia o no pérdida del sí mismo ha sido confundida con la no-historicidad. Pero no son contrarios, sino dos aspectos complementarios del sí mismo, que mantienen entre sí una relación dialéctica. En una cultura masificada, el hombre cuestiona su identidad personal y colectiva, como se describe en L'Homme sans qualités (El hombre sin atributos) de Roberto Musil. Los cuatro tomos difuminan, no obstante, el personaje, de manera que

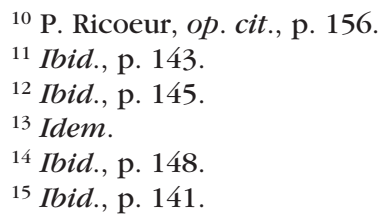


esta obra está más cerca del ensayo que del relato. Se asemeja a los puzzling cases, centrados aquí en el soportar la dominación. Todo queda en el otro, en la ipseidad impuesta a un lugar vacío. Este libro versa sobre un desconcertante caso límite porque cuando el personaje dice "no soy nada", continúa siendo un sí mismo, sólo que es innombrable (¿como los personajes de Kafka?, me pregunto): la pregunta carece de sentido.

3. La dialéctica entre la mismidad y la ipseidad encuentra un medio idóneo en la narración, en el mytho, esto es, en la historia y literatura (novela, epopeya, cuento y drama), porque integran una unidad dialéctica entre: unidad o centro que permanece y diversidad, variación, lo discontinuo; la historia (story) llena de lagunas de lo temporal. La trama revela los existenciarios ${ }^{16}$ que registró Heidegger: la existencia del protagonista tiene un carácter único; lo que la "sedimentación ha contraído", el desarrollo de la trama lo vuelve a desplegar: ${ }^{17}$ la narración construye la identidad del personaje dentro de la exigencia aristotélica de la concordancia y la discordancia, ${ }^{18} \mathrm{O}$ trastocamiento de la fortuna entre la situación de inicio y el final, en una síntesis de lo heterogéneo, que rehace la dispersión episódica. El relato describe intenciones de la persona y causas que la rebasan, dejando entrever los hechos que podrían haber sido de otra manera o no ser, aunque el entramado les otorga una probabilidad, consignando también lo sorprendente e inesperado que refleja el azar y la autonomía personal: el personaje actúa de una manera entre la ilimitada capacidad que tuvo de haber actuado, en palabras de Hegel-Fenomenología del espíritu- que Ricoeur hace suyas.

Si Aristóteles puso en el lugar de privilegio a la trama (al mytho), y Ricoeur admitió esto en Tiempo y narración I, en Sí mismo precisa que los personajes sí son clave, porque desde su identidad o articulación única o totalidad singular, se entrama. Si desaparecieran, el texto se volvería únicamente argumentación o pensamiento discursivo (diánoia). En los inicios de los relatos, época en que se hablaba simbólicamente de dioses mediante recurrentes caracteres inamovibles, cuyas huellas quedaron en los cuentos folclóricos o de hadas, después la literatura y la historia se ocuparon de personajes reales, con cuerpo y una identidad, hecho que obligó a narrar más. ${ }^{19}$ El hábeas básico con que trabaja Propp en la Morfología del cuento le sugirió que los personajes eran reductibles a funciones. La génesis literaria de verdaderas identidades trajo consigo su descripción como agentes y pacientes (según Bremond) o reales "actantes" (según el modelo actancial de Greimas) que se comportan

\footnotetext{
16 Ibid., p. 149.

${ }^{17}$ Ibid., p. 148.

${ }^{18}$ Ibid., p. 168.

${ }^{19}$ Ibid., p. 172.
} 
"en vistas a": recogiendo las aporías del tiempo, sus deseos generan una previsión del futuro. El relato consigna la retrospección y la prospección o anticipaciones con sus "horizontes de espera" ${ }^{20}$ Dependiendo de su plan de vida, el personaje se desarrolla entre adyuvantes y convergentes $u$ oponentes o rivales, ${ }^{21}$ lo que facilita incluso describir las consecuencias no previstas de su acción que generaron una nueva cadena de hechos, o sea, una relación entre el todo social y la parte agente o actante.

El destinatario o receptor del texto interpreta en qué situación o quién actuó, y por qué y cómo lo hizo a partir de la identidad única y dinámica de los personajes. De manera más o menos intuitiva, los aprueba o no aprueba, dependiendo de si los ideales que rigieron sus comportamientos estuvieron dentro de la esperanza de una vida buena, es decir, para y con los otros en instituciones justas, ${ }^{22}$ y de si los imperativos morales con estatuto deóntico (la autonomía, el diálogo y respeto del otro y el contrato social o regla de oro) fueron norma de sus conductas; es decir, que penetra en el "cuidado" $(\text { Sorge })^{23}$ del sí mismo, en sus preocupaciones por todo aquello y quienes le concernieron.

Los rasgos de la identidad que aparecen en la narración son el "primer laboratorio del juicio moral) ${ }^{24}$ porque ningún relato, ni siquiera el historiográfico, tiene el grado cero de la estimación moral: no existe un solo neutral, ${ }^{25}$ dice Ricoeur con MacIntyre -After Virtue, a Study in Moral Theory.

4. Todo relato de vida tiene algo de ficción; en tanto es una perspectiva entre muchas, se pueden trazar varias trayectorias de una vida, y engarzar los actos de distinta manera. Lo único que ofrecen la historia y la literatura bien logradas es una "atestación" o testimonio creíble y veritativo. ${ }^{26}$ Entre el relato autobiográfico y el que utiliza la tercera persona, o autor omnisciente, media una gran distancia. El primero está abierto en los extremos: ni el nacimiento ni la muerte pertenecen al narrador; mientras que el relato literario puede reunir principio, medio y fin (aunque el texto los ordene de otra manera). Ricoeur aduce esta diferencia en tanto una no coincidencia suya con MacIntyre. Sin embargo, existen relatos literarios que no consideran ni el nacimiento ni la muerte del protagonista, que también es el narrador, ni ambos describen los extremos de vida aun teniendo una tercera persona o narrador omnisciente.

\footnotetext{
${ }^{20}$ Ibid., p. 191.

${ }^{21}$ Ibid., p. 173.

22 Ibid., pp. 237-278.

${ }^{23}$ Ibid., p. 359.

${ }^{24}$ Ibid., p. 167.

${ }^{25}$ Ibid., pp. 137 y 167.

${ }^{26}$ Ibid., p. 347.
} 
En suma, el arte de narrar es, dice Ricoeur con Walter Benjamin -Illuminationem-, el de intercambiar experiencias. Y agrega que por su identidad personal, o por su conexión de vida, amamos u odiamos a los personajes -identidades idem e ipse-, es decir, que en la vida y la literatura opera simpatía o la antipatía debidas a: los pensamientos, acciones, pasiones, y a la despreocupación o bien a los cuidados por una vida buena. 